\title{
Financial Planning for Retirement in Young Adults: Interaction of Professional Experience, Knowledge, and Beliefs
}

\author{
Viera Bačová, Katarína Dudeková, Lenka Kostovičová \\ Institute of Experimental Psychology \\ Center of Social and Psychological Sciences, \\ Slovak Academy of Sciences \\ Vladimír Baláž \\ Institute for Forecasting \\ Center of Social and Psychological Sciences, \\ Slovak Academy of Sciences
}

\begin{abstract}
The aim of the present study was to examine the impact of professional financial experience on the relationships between financial knowledge and beliefs on financial planning for retirement (FPR) in young adults. We designed a domain-specific personal belief inventory comprising all important components involved in FPR. Financial professionals $(n=145)$ demonstrated greater knowledge of the financial retirement system compared with non-professionals $(n=382)$. The two groups, however, differed neither in objective nor self-rated general financial literacy. In non-professionals, higher financial literacy was positively linked to trust in the 2 nd pension pillar, self-assessed competence in FPR, personal engagement in FPR, perceiving FPR as less emotionally loaded and FPR task as less complex. These predicted relationships were not found among professionals. Thus, professional experience in financial domain seems to bring a deeper and particularized insight into the pros and cons of the pension system, and consequently vacillates beliefs about FPR.
\end{abstract}

Key words: financial planning for retirement, financial professional experience, financial literacy, personal beliefs, young adults

\section{Introduction}

Young people in Slovakia are facing a very high-consequence financial decision soon after entering their first job as they must decide whether tojoin the $2^{\text {nd }}$ pension pillar. Since 2004 the $2^{\text {nd }}$ pension pillar presents a new possibility of financial planning for retirement (hereafter FPR) in Slovakia. While in the $1^{\text {st }}$ pension pillar

This research was supported by grant APVV-036112 - 'Decision Making of Professionals: Process, personality and Social Aspects'.

Correspondence concerning this paper should be addressed to Viera Bačová, Institute of Experimental Psychology, Center of Social and Psychological Sciences SAS, Dúbravská cesta 9,84104, Bratislava, Slovak Republic. E-mail: viera.bacova@savba.sk

Received November 4, 2016 employees can count on a defined level of retirement benefits based on a computation that reflects their salary and years of service (DB pension), in the $2^{\text {nd }}$ pillar employees invest their contributions in pension funds at one of the private financial institutions. The $2^{\text {nd }}$ pension pillar in Slovakia represents a type of defined contribution plan (DC pension), where retirement income is calculated on the basis of the worker's level of pre-retirement contributions. Unlike the $1^{\text {st }}$ state pillar, participation in the private $2^{\text {nd }}$ pillar is not mandatory for Slovak employees nowadays. At the same time, only people up to 35 years can enroll in the $2^{\text {nd }}$ pillar.

The decision of an individual employee whether to enter the $2^{\text {nd }}$ pillar has far-reaching consequences because a process of undergoing finance reform comprises the massive shift from defined benefit (DB) to defined contribution (DC) retirement plans for young adults. The 
changes in the retirement income system are aimed at an increase in responsibility for one's retirement income that will no longer be determined by one's employer and the state, but instead will largely depend on the saving and investment decisions of an individual employee. Yet many legal and economic changes, which accompany the $2^{\text {nd }}$ pension pillar system in Slovakia from its inception until now, make this decision-making environment rather unclear and difficult to understand.

In addition to enrolling in the $2^{\text {nd }}$ pillar, there are many other decisions young people need to make with regard to FPR, such as investment choices in the $2^{\text {nd }}$ pillar or participation in the $3^{\text {rd }}$ pillar. These high consequence choices find most young people quite unprepared. Indeed, despite the importance of the financial decisions that young adults need to make, financial retirement planning decisions remain an area within which individuals receive little formal and/ or informal education.

Studies on financial preparation for retirement have focused mostly on demographic indicators associated with FPR among all people of working age or they focused on older individuals approaching retirement. In the present study we examine the psychological, cognitive and motivational forces that underlie planning and saving for retirement in young people. Factual financial knowledge, financial hands-on experience, and personal beliefs on FPR are explored as important psychological variables which can broaden our understanding of the psychological forces that drive young people to prepare financially for their retirement.

\section{Financial Knowledge and FPR}

Factual knowledge and understanding of financial matters are arguably one of the necessary prerequisites of the ability to make personal financial decisions efficiently (Croy, Gerrans, \& Speelman, 2010; Hershey, Austin, \&
Gutierrez, 2015; Lusardi \& Mitchell, 2011a, $2011 b)$. There is a wealth of evidence that insufficient financial knowledge in adulthood results in a range of negative outcomes. For instance, a low level of financial literacy and numeracy have been identified as the root cause of poor retirement saving and investment decisions (Lusardi \& Mitchell, 2011a, 2011b). Many studies show that engagement in planning for retirement and saving rates are deeply impacted by one's level of financial and investment knowledge (Croy et al., 2010; Van Rooij, Lusardi, \& Alessie, 2011). According to recent research of retirement saving across eight European countries, financial literacy positively influences retirement savings, so that individuals with a higher level of financial knowledge show a greater tendency to save for retirement (Fernández-López, Otero, Vivel, \& Rodeiro, 2010).

\section{Practical Financial Experience}

Since the field of finance is considerably broad, when it comes to real-world personal decisions, it is both financial knowledge and practical skills that largely determine financial performance of an individual. The adequate personal financial decision assumes not only knowledge of theoretical financial concepts but a hands-on financial experience. One's financial experiential knowledge, i.e. math skills, number-crunching, data organization and analyses, computational skills, information search practice, or decision-making scripts is likely to outweigh the relative value of more general knowledge and abilities (Čavojová \& Hanák, 2014; Hershey, Austin, \& Gutierrez, 2015). Yet people, especially the young ones, often lack this handson financial experience.

The above-mentioned financial practical experience and procedural knowing are likely to be acquired in professions where individuals encounter various types of practical financial 
tasks and have repeated experience with plenty of the same types of financial decisions. We assume that practice, even in low level financial professions (such as accountants, invoice and pay clerks), can develop these basic financial skills and knowledge. Due to the exposure to these types of financial tasks through performing financial occupations, increased financial expertise can be expected (Hibbert, Lawrence, \& Prakash, 2012).

\section{Personal Beliefs about FPR}

Personal beliefs about certain area of the world have been an important field of psychological research for a long time since they influence a variety of behaviors. Ajzen and Fishbein (2000) defined beliefs as the "subjective probability that the object has a certain attribute" (p. 4). While attitudes are considered more affective, beliefs are supposed to be more cognitive (Fishbein \& Ajzen, 1975). In social sciences beliefs are seen as understandings, premises or propositions about the world and self that people take as true. On the contrary, knowledge has higher epistemic status than beliefs, given its justifiable, supportable claims (Hofer \& Pintrich, 1997). In fact, some authors consider attitudes and beliefs to be an integrated part of knowledge. For example, Mayer (2009) distinguishes five kinds of knowledge - factual, conceptual, procedural, strategic, and attitudinal knowledge. Attitudinal knowledge involves beliefs about self-efficacy, interests, attributions, values, and goals which affect task performance (Mayer, 2009). To perform complex cognitive tasks, all types of knowledge need to be involved and trained.

Retirement planning activities of individuals may vary both as a function of financial cognitive competence, and objectively unjustifiable beliefs about the nature of financial world and particular norms, possibilities, tasks, and demands of various financial activities which an individual holds. Hershey, Henkens, and Dalen (2010) express this very clearly: "it is one's subjective world that serves to structure individuals' perceptions of financially-related opportunities and constraints" (p. 2). Beliefs about one's own abilities, for example, can be motivating, since they encourage performance and mastery goals. Similarly, beliefs of an individual about the difficulty of the task may hinder him/her to initiate this task. Thus, personal beliefs about external and internal conditions of FPR shape behavior in both positive and negative way, since they influence how individuals approach the task in terms of their motivation and cognition. Personal FPR beliefs may, for instance, impede motivation to persist with difficult FPR problems, although in these the long-term efforts are conducive to success. Both individual abilities (knowledge and experience) and personal beliefs about the FPR problems and about one's own prerequisites to succeed in the respective tasks may account for high-quality financial preparation for retirement.

Empirical evidence of the role of psychological constructs in retirement planning and saving behavior is scarce. Hershey, JacobsLawson, McArdle, and Hamagami (2007) examined future time perspective, retirement goal clarity, and self-rated financial knowledge as psychological factors involved in the retirement planning process. Within the frame of the theory of planned behavior, Croy et al. (2010) examined, among others, beliefs which influence retirement saving behaviors. Participants' evaluation of the importance of retirement planning and self-rated preparedness for this planning predicted behavioral intentions to save more and to actively manage investment strategy. Noone, Stephens, and Alpass (2010) developed the Process of Retirement Planning Scale, which consists of items for retirement representation, retirement goals, the decision to prepare for retirement and preparedness. Since we focus here on young 
people only, for whom the idea of retirement is too far in the future, we have developed our own instrument to capture beliefs of young people concerning all aspects of their current conditions of FPR (see section Materials and Measures for more details).

\section{The Present Research}

This study is aimed to examine the differences in financial knowledge, personal FPR beliefs and current retirement saving according to professional financial experience, and to clarify the role of professional financial experience within relationships between financial knowledge and FPR beliefs in young adults.

Firstly, we were interested whether young people working in non-financial versus financial employments (hereafter non-professionals and professionals) differ in financial literacy, personal beliefs about FPR and current retirement savings. Professionals might be expected to have better financial knowledge and more nuanced and realistic view of retirement financial preparation, and to save more for retirement, due to competences developed in the course of performing their finance-related profession on a daily basis.

Next, we aimed at examining the interactions between financial literacy and financial professional experience in relation to personal beliefs on FPR. We would expect higher financial knowledge (especially retirement financial literacy) of the participants to be associated with positive personal beliefs about FPR, such as perceiving the FPR task as more urgent and less demanding. Our main concern was to determine the impact of professional financial experience on the links between financial knowledge and personal beliefs in more details. In other words, we were interested whether the relationship between financial literacy and personal beliefs about FPR depends on professional experience in the financial domain.
Last but not least, given the absence of any instrument to assess attitudes and beliefs about FPR in Slovakia, our final objective was to fill the gap. Therefore, we designed a domain-specific personal belief inventory, comprising all the important components that are involved in financial preparation for retirement, i.e. sociolegal environment of FPR, FPR task, and one's capacity and motivation for FPR. The beliefs inventory has been tailored for the specific conditions of financial retirement planning of young people, where the timing of saving start and the form it should take have been normatively determined.

\section{Method}

\section{Participants}

\section{Financial Non-Professionals}

In the first phase of data collection we used an online questionnaire. A sample of 602 young employed adults was recruited, aged 20 to 35 years. The sample was balanced with regard to geographical region, gender, and income group quotas, representative for respective Slovak population. We implemented several exclusion criteria to enhance reliability of our results. Thus, we excluded those participants who failed to pass the control item $(n=146)$, whose answers were ambiguous ("neither agree nor disagree") in more than a half of the items on FPR beliefs $(n=39)$, who did not know whether they are enrolled in the $2^{\text {nd }}$ pension pillar $(n=15)$, and whose professions belong to the financial domain $(n=20)$. Consequently, we analyzed the responses from the remaining 382 participants (157 females, 225 males; $M=29.7$ years, $S D=$ 3.9). More than a half of the sample of nonprofessionals $(n=224)$ had a university degree and less than five percent $(n=17)$ completed only primary school or a secondary school without graduation. 


\section{Financial Professionals}

In the second phase, the data were collected face to face. The original sample consisted of 157 young adults working in the domain of finance. Again, we excluded participants who provided ambiguous ("neither agree nor disagree") answers in more than a half of the items on FPR beliefs $(n=12)$. We further report results based on analyses of the responses from the remaining 145 participants (118 females, 27 males; $M=30.5$ years, $S D=3.7)$. Gender composition of the sample corresponds to the actual ratio of men and women (2:8) among professions such as economist or accountant, according to the Statistical Office of the Slovak Republic. The following financial professions were included in the sample: accountants $(40.7 \%)$, economists $(26.9 \%)$, invoice clerks $(15.2 \%)$, pay clerks and personnel managers $(11.0 \%)$, financial officers $(3.4 \%)$, and others $(2.8 \%)$. The participants have been working in their current positions 4.3 years on average $(S D=2.9)$. Half of the sample of financial professionals had a university degree $(n=73)$ and the other half completed secondary school with graduation $(n=72)$. They reported 1 to 18 years of professional experience in financial domain $(M=6.0 ; S D=3.8)$.

\section{Design and Procedure}

The whole data collection process, including parts that are not reported here, was conducted by a marketing agency from December 2015 to March 2016. The sample of non-professionals was recruited through an online panel of the agency, which currently consists of 13,000 active members from Slovakia, who are rewarded for research participation with financial credit. After brief information about the research, an informed consent and instructions, participants answered a set of socio- demographic questions. Next, they were asked to assess their understanding of financial matters (i.e., self-rated financial literacy) and to answer the items of the objective financial literacy tests. Subsequently, the participants expressed their personal beliefs about financial planning for retirement on Likert scales corresponding to 52 statements. Finally, they answered questions about their current retirement savings (see section Materials and Measures for more details).

Financial professionals were recruited using a mixed method, based on stratified random sampling from databases, telephone screening, and face-to-face administration of the questionnaire. The interview lasted about 30 minutes. Two basic criteria were set for the participants: their professions had to include working with information about the pension system, and the length of their professional experience in financial domain had to be at least one year. The content of the questionnaire as well as the order of the measures was the same as in the online version for non-professionals, with the following exceptions. The participants answered supplementary questions regarding their professional experience, and they completed a shorter (26-item) version of the Beliefs about FPR scales (see section Materials and Measures for more details).

\section{Materials and Measures}

\section{Financial Literacy and Current Retire- ment Savings}

\section{Objective Financial Literacy}

The basic financial literacy subscale consisted of three questions which have been widely used in international research (e.g., Bucher-Koenen \& Lusardi, 2011; Lusardi \& Mitchell, 2011a, 2011b; Van Rooij et al., 2011). The subscale aims at measuring knowledge of 
rather simple economic concepts such as inflation, interest, and risk diversification. For a more precise discrimination of participants' knowledge of financial matters, we used another set of three items as a measure of sophisticated financial literacy. The subscale concerns comprehension of financial operations such as compound interest, and complex choice of financial products.

\section{Objective Retirement Financial Literacy}

Knowledge of the overall retirement financial system in Slovakia was examined with 13 items (i.e., 1 item addressed the pension system in Slovakia, 4 items addressed the $1^{\text {st }}$ pension pillar, 6 items addressed the $2^{\text {nd }}$ pillar, and 2 items addressed the $3^{\text {rd }}$ pillar). We used binary coding (correct/incorrect) for all the items of the two objective financial literacy tests. A higher score indicates a higher level of literacy.

\section{Self-rated Financial Literacy}

For eliciting subjective estimate of one's understanding of financial matters, we used the following question with respective 5-item Likert scale: "To what extent do you understand economic matters, such as interest, inflation, mortgage and the like?" (1: "I do not understand at all"; 5: "I understand very well").

\section{Current Retirement Savings}

We used an additional set of measures of saving behavior. We were interested whether - and to what extent - non-professionals and financial professionals actually engage in financial preparation for retirement. As the enrollment in the $2^{\text {nd }}$ and/or the $3^{\text {rd }}$ pillar necessitates longterm regular saving within selected schemes we inquired about participation in the $2^{\text {nd }}$ pillar, in the $3^{\text {rd }}$ pillar, and the savings for retirement beyond the pillars (i.e., other investments). Be- sides the three dichotomous indicators, we created a measure representing the number of saving "methods" in addition to the $1^{\text {st }}$ pillar (e.g., $2^{\text {nd }}$ pillar $+3^{\text {rd }}$ pillar $=2$ ).

\section{Personal Beliefs about FPR}

We developed our inventory of beliefs assumed to determine FPR. Fifty-two statements were gathered by the research team to capture the main components of the FPR process: sociolegal environment of FPR, FPR task, and decision maker capacity and motivation for FPR. According to the decision theories (e.g., Payne, Bettman, \& Johnson, 1993), these factors are involved in decision-making and thus we assumed that they also enter the decision processes on FPR.

The items concerned assessment of social and legal environment of FPR, and trust in the economic system of the society, specifically reliance on state social security in FPR. The next category of items focused on perception and evaluation of relevance, feasibility, and complexity of the FPR task. The final set of statements contained self-evaluation of participants' characteristics, such as their perception of the future, financial risk attitudes, motivation for FPR, self-rated FPR personal competence, financial stress and anxiety, and locus of control (see section Materials and Measures, and Appendix for more details).

The fifty-two items were administered to 602 participants working in non-financial professions. The participants expressed their level of agreement with the statements on 5-point Likert scales (1: "strongly disagree"; 5: "strongly agree"). After excluding participants who failed to pass the control item and those who replied ambiguously ("neither agree nor disagree") most of the time, we entered the answers of the remaining 417 non-professionals into exploratory factor analysis (principal components method). 
A maximum likelihood extraction with varimax rotation was used, without limitation on the number of factors. Thirteen eigenvalues greater than one resulted from this analysis $(K M O=$ .874 , Bartlett's test of sphericity: $p<.001)$. However, the pattern of loadings, visual inspection of the scree plot suggested and content analysis of the potential factors led us to end up with a five-factor solution of the „Beliefs about financial planning for retirement": (1) The trust in the $2^{\text {nd }}$ pillar -3 items, (2) FPR task complexity -6 items, (3) FPR personal engagement -7 items, (4) FPR emotional load - 5 items, and (5) FPR personal competence -5 items. These five factors explain over $40 \%$ of the total variability in the data.

After administration of the scales to the group of financial professionals and subsequent basic psychometric analysis, we decided to exclude three items in order to reach a higher reliability of three scales (the trust in the $2^{\text {nd }}$ pillar, FPR task complexity, and FPR personal competence). Thus, the final version of the beliefs about FPR measure contained 23 items. The alpha coefficients for the scales within the group of non-professionals and financial professionals are listed in Table 1.

In the two-item scale The trust in the $2^{\text {nd }}$ pillar participants expressed their belief that saving in the $2^{\text {nd }}$ pillar will result in improvement of their standard of living in retirement. Beliefs about their own competence in FPR have been assessed by four items on one's own knowl- edge of possibilities for financial preparation for retirement on the scale FPR personal competence. The seven-item scale on the FPR personal engagement in financial preparation for retirement focused on the perceived need for an early start of retirement financial preparation. The demands of the task to prepare financially for retirement, and difficulties of entering and participating in the $2^{\text {nd }}$ pillar, have been assessed by five items of the scale FPR task complexity. Anxiety and stress that accompanies financial planning and decision making, along with a possible lack of financial resources was measured by five items of the scale FPR emotional load. A higher score in the scale means a higher level of the belief. All scales are attached in the Appendix.

\section{Results}

Comparison of Professionals and Non-Professionals in Financial Literacy, Retirement Savings, and Beliefs about FPR

\section{Differences in Financial Literacy and Cur- rent Retirement Savings}

Table 2 depicts the comparisons of financial professionals and non-professionals on financial literacy scales. The professionals reached a significantly higher score in retirement financial literacy compared with non-professionals. However, the two groups differed neither in

Table 1 Internal consistency of the Beliefs about FPR scales in professionals and non-professionals

\begin{tabular}{lccc}
\hline & Items & Non-professionals & Professionals \\
\hline Trust in the $2^{\text {nd }}$ pillar & 2 & $\alpha=.75$ & $\alpha=.73$ \\
FPR task complexity & 5 & $\alpha=.80$ & $\alpha=.74$ \\
FPR personal engagement & 7 & $\alpha=.79$ & $\alpha=.84$ \\
FPR emotional load & 5 & $\alpha=.78$ & $\alpha=.80$ \\
FPR personal competence & 4 & $\alpha=.77$ & $\alpha=.67$ \\
\hline
\end{tabular}


understanding of basic and sophisticated economic matters nor in self-rated financial literacy. It should be noted that half of the participants in both groups reached at least 5 out of total 6 points in the financial literacy scale, and at least 11 out of total 13 points in the retirement financial literacy scale. Thus, the tests did not discriminate well in our samples.

Moreover, as depicted in Table 3, we also failed to find differences between financial pro- fessionals and non-professionals in any of the measures of current retirement savings. More than seventy percent of both groups are enrolled in the $2^{\text {nd }}$ pillar ( $70.9 \%$ of non-professionals and $77.2 \%$ of professionals), more than thirty percent are enrolled in the $3^{\text {rd }}$ pillar $(32.2 \%$ of non-professionals and $40.7 \%$ of professionals), and about thirty percent save for their retirement beyond the pillars $(28.3 \%$ of non-professionals and $33.1 \%$ of professionals).

Table 2 Differences between non-professionals and professionals in financial literacy (FL)

\begin{tabular}{|c|c|c|c|}
\hline & Non-professionals & Professionals & Comparison \\
\hline \multirow{2}{*}{$\mathrm{FL}$ - basic } & $\operatorname{Min}=0, \operatorname{Max}=3$ & $\operatorname{Min}=0, \operatorname{Max}=3$ & \multirow{2}{*}{$\begin{array}{c}U=26020.0, p=.220 \\
r_{m}=.05\end{array}$} \\
\hline & $\operatorname{Mdn}=3.0(1.0)^{* *}$ & $\operatorname{Mdn}=3.0(1.0)^{*}$ & \\
\hline \multirow{2}{*}{ FL - sophisticated } & $\operatorname{Min}=0, \operatorname{Max}=3$ & $\operatorname{Min}=0, \operatorname{Max}=3$ & \multirow{2}{*}{$\begin{array}{c}U=26387.0, p=.371 \\
r_{m}=.04\end{array}$} \\
\hline & $\operatorname{Mdn}=2.0(1.0)^{* * *}$ & $\operatorname{Mdn}=2.0(1.0)^{*}$ & \\
\hline \multirow{2}{*}{$\mathrm{FL}$ - overall } & $\operatorname{Min}=0, \operatorname{Max}=6$ & $\operatorname{Min}=0, \operatorname{Max}=6$ & \multirow{2}{*}{$\begin{array}{c}U=27601.5, p=.951 \\
r_{m}<.01\end{array}$} \\
\hline & $\operatorname{Mdn}=4.0(1.0)^{*}$ & $\operatorname{Mdn}=4.0(1.0)^{* *}$ & \\
\hline \multirow{2}{*}{ Retirement FL } & $\operatorname{Min}=1, \operatorname{Max}=13$ & $\operatorname{Min}=4, \operatorname{Max}=13$ & \multirow{2}{*}{$\begin{array}{c}U=23392.5, \boldsymbol{p}=\mathbf{. 0 0 5} \\
r_{m}=.12\end{array}$} \\
\hline & $\operatorname{Mdn}=11.0(3.0)^{* *}$ & $\operatorname{Mdn}=11.0(2.0)^{* *}$ & \\
\hline \multirow{2}{*}{ Self-rated FL } & $\operatorname{Min}=1, \operatorname{Max}=5$ & $\operatorname{Min}=2, \operatorname{Max}=5$ & \multirow{2}{*}{$\begin{array}{c}U=27504.0, p=.896 \\
r_{m}=.01\end{array}$} \\
\hline & $\mathrm{Mdn}=3.0(1.0)$ & $\mathrm{Mdn}=3.0(1.0)$ & \\
\hline
\end{tabular}

Note. Values in parentheses stand for interquartile ranges. Values in bold represent significant differences.

* Negatively skewed distribution

** Negatively skewed \& Leptokurtic (thin) distribution

*** Platykurtic (flat) distribution

Table 3 Differences between non-professionals and professionals in current retirement savings

\begin{tabular}{lccc}
\hline & Non-professionals & Professionals & Comparison \\
\hline $2^{\text {nd }}$ pillar & $70.9 \%$ & $77.2 \%$ & $\chi^{2}(1)=2.1 ; p=.156 ; \varphi=.06$ \\
$3^{\text {rd }}$ pillar & $32.2 \%$ & $40.7 \%$ & $\chi^{2}(1)=3.4 ; p=.081 ; \varphi=.08$ \\
Other savings & $28.3 \%$ & $33.1 \%$ & $\chi^{2}(1)=1.2 ; p=.287 ; \varphi=.05$ \\
& $0: 23.0 \%$ & $0: 19.3 \%$ & \\
Overall savings & $1: 35.6 \%$ & $1: 31.7 \%$ & \multirow{2}{*}{$\chi^{2}(3)=5.8 ; p=.120 ; \varphi=.11$} \\
& $2: 28.3 \%$ & $2: 27.6 \%$ & \\
& $3: 13.1 \%$ & $3: 21.4 \%$ & \\
\hline
\end{tabular}




\section{Differences in Beliefs on FPR}

Comparisons of the two groups in beliefs on financial planning for retirement in Table 4 reveal that professionals rated themselves as more competent but less personally engaged in FPR than non-professionals. However, no significant differences were observed regarding the trust in the $2^{\text {nd }}$ pillar, FPR task complexity, and FPR emotional load.

Relationships Between Knowledge and Beliefs about FPR

In the subsequent analyses, we looked closely at the relationships between financial literacy and beliefs about FPR, according to professional experience (Table 5). Among non-professionals, all types of financial literacy were positively correlated with the trust in the $2^{\text {nd }}$ pillar, perceived FPR personal engagement and FPR personal competence, and negatively correlated with perceived FPR task complexity and FPR emotional load. Interestingly, we did not identify any association between objective measures of financial literacy and beliefs about FPR among financial professionals. However, the more professionals rated themselves as financially literate, the less emotional load they felt, considered themselves more competent for FPR, and perceived the higher FPR personal engagement. In addition, subjective and objective measures of financial literacy correlated only among nonprofessionals.

Role of Professional Experience in Relationships Between Knowledge and Beliefs about FPR

Since the presence of significant relationships in one group and its absence in the other does not guarantee a central role of professional experience, we proceeded with series of

Table 4 Differences between non-professionals and professionals in beliefs about FPR

\begin{tabular}{|c|c|c|c|}
\hline & Non-professionals & Professionals & Comparison \\
\hline $\begin{array}{l}\text { Trust in the } 2^{\text {nd }} \\
\text { pillar }\end{array}$ & $\begin{array}{l}\operatorname{Min}=1.0, \operatorname{Max}=5.0 \\
\operatorname{Mdn}=3.5(1.0)^{*}\end{array}$ & $\begin{array}{l}\operatorname{Min}=1.0, \operatorname{Max}=5.0 \\
\operatorname{Mdn}=3.5(1.5)\end{array}$ & $\begin{array}{c}U=27634.0, p=.968 \\
r_{m}<.01\end{array}$ \\
\hline $\begin{array}{l}\text { FPR task } \\
\text { complexity }\end{array}$ & $\begin{array}{l}\operatorname{Min}=1.0, \operatorname{Max}=5.0 \\
M=2.6(0.9)\end{array}$ & $\begin{array}{l}\operatorname{Min}=1.0, \operatorname{Max}=4.6 \\
M=2.6(0.8)\end{array}$ & $\begin{array}{c}t(525)=0.7, p=.487 \\
d=0.07\end{array}$ \\
\hline $\begin{array}{l}\text { FPR personal } \\
\text { engagement }\end{array}$ & $\begin{array}{l}\operatorname{Min}=1.4, \operatorname{Max}=5.0 \\
\operatorname{Mdn}=3.7(1.0)^{*}\end{array}$ & $\begin{array}{l}\operatorname{Min}=1.3, \operatorname{Max}=5.0 \\
\operatorname{Mdn}=3.4(1.4)^{* *}\end{array}$ & $\begin{array}{c}U=24166.5, \boldsymbol{p}=. \mathbf{0 2 4}, \\
r_{m}=.10\end{array}$ \\
\hline $\begin{array}{l}\text { FPR emotional } \\
\text { load }\end{array}$ & $\begin{array}{l}\operatorname{Min}=1.0, \operatorname{Max}=5.0 \\
\operatorname{Mdn}=2.6(1.4)\end{array}$ & $\begin{array}{l}\operatorname{Min}=1.0, \operatorname{Max}=4.8 \\
\operatorname{Mdn}=2.6(1.8)^{* *}\end{array}$ & $\begin{array}{c}U=26064.0, p=.295 \\
r_{m}=.05\end{array}$ \\
\hline $\begin{array}{l}\text { FPR personal } \\
\text { competence }\end{array}$ & $\begin{array}{l}\operatorname{Min}=1.0, \operatorname{Max}=5.0 \\
\mathrm{M}=3.2(0.8)\end{array}$ & $\begin{array}{l}\operatorname{Min}=1.5, \operatorname{Max}=5.0 \\
\mathrm{M}=3.5(0.7)\end{array}$ & $\begin{array}{c}t(525)=-3.8, \boldsymbol{p}<\mathbf{. 0 0 1}, \\
d=0.37\end{array}$ \\
\hline
\end{tabular}

Note. All values were standardized to an identical range - 1 to 5 - in line with the original 5point Likert scale. Values in parentheses stand for standard deviations or interquartile ranges. Values in bold represent significant differences.

* Negatively skewed distribution

** Platykurtic (flat) distribution 
Table 5 Correlations between knowledge and beliefs about FPR among non-professionals and professionals

\begin{tabular}{lcccccc}
\hline & \multicolumn{2}{c}{ Financial literacy } & \multicolumn{2}{c}{$\begin{array}{c}\text { Retirement } \\
\text { financial literacy }\end{array}$} & \multicolumn{2}{c}{$\begin{array}{c}\text { Self-rated } \\
\text { financial literacy }\end{array}$} \\
\cline { 2 - 7 } & N-P & FP & N-P & FP & N-P & FP \\
\hline Trust in the $2^{\text {nd }}$ pillar & $.17^{*}$ & -.01 & $.35^{*}$ & .23 & $.25^{*}$ & .12 \\
FPR task complexity & $-.20^{*}$ & -.03 & $-.39^{*}$ & -.15 & $-.39^{*}$ & -.08 \\
FPR personal engagement & $.21^{*}$ & .15 & $.34^{*}$ & .16 & $.29^{*}$ & $.26^{*}$ \\
FPR emotional load & $-.25^{*}$ & -.13 & $-.30^{*}$ & -.14 & $-.39^{*}$ & $-.29^{*}$ \\
FPR personal competence & $.30^{*}$ & .11 & $.36^{*}$ & .03 & $.58^{*}$ & $.31^{*}$ \\
Financial literacy & - & - & $.42^{*}$ & $.34^{*}$ & $.34^{*}$ & .19 \\
Retirement fin. literacy & - & - & - & - & $.32^{*}$ & .02 \\
\hline
\end{tabular}

Note. $\mathrm{N}-\mathrm{P}=$ non-professionals, $\mathrm{FP}=$ financial professionals

$* p<.0028$ (after applying Bonferroni correction)

moderation analyses using the SPSS macro PROCESS (Hayes, 2013). Moderation analysis in a regression-based analytical approach aimed at investigating whether a certain variable is related to the size of one variable's effect on another. Identifying a moderator helps to establish the boundary conditions of an effect or the circumstances or type of people for which the relationship is absent versus present, weak versus strong, negative versus positive. In all our moderation analyses, professional experience acted as a potential moderator of the relationships between financial knowledge and FPR beliefs. In addition, given the different proportion of men and women among financial professionals and non-professionals, we added gender into the analyses as a covariate. ${ }^{1}$

Prior to testing the models, we checked the data for multicollinearity, presence of outliers and influential cases, and autocorrelation in the residuals. We placed financial literacy in the role of focal predictor in the first set of tested mod-

\footnotetext{
${ }^{1}$ We would like to thank the anonymous reviewers for this suggestion and all their valuable comments which helped us refine the manuscript.
}

els and changed it for retirement financial literacy in the second set and for self-rated financial literacy in the last set. We found three significant models, as described below.

Professional experience moderated the effect of retirement financial literacy (RFL) on FPR personal competence (Figure 1), and the effects of self-rated financial literacy (SFL) on FPR personal competence (Figure 2) and FPR task complexity (Figure 3). The effects of the two indicators of financial literacy on FPR personal competence and FPR task complexity were substantially higher among non-professionals, and non-significant in the first and the last model among professionals. The first model based on interaction of RFL and professional experience, controlling for the effect of gender, explained $12 \%$ of variance in perceived FPR personal competence $(p<0.001)$. The other two models based on interaction of SFL and professional experience, controlling for the effect of gender, explained $31 \%$ of variance in perceived FPR personal competence $(p<0.001)$ and $13 \%$ of variance in perceived FPR task complexity $(p<0.001)$. Gender, as the covariate, was a significant predictor of FPR emotional load only. 


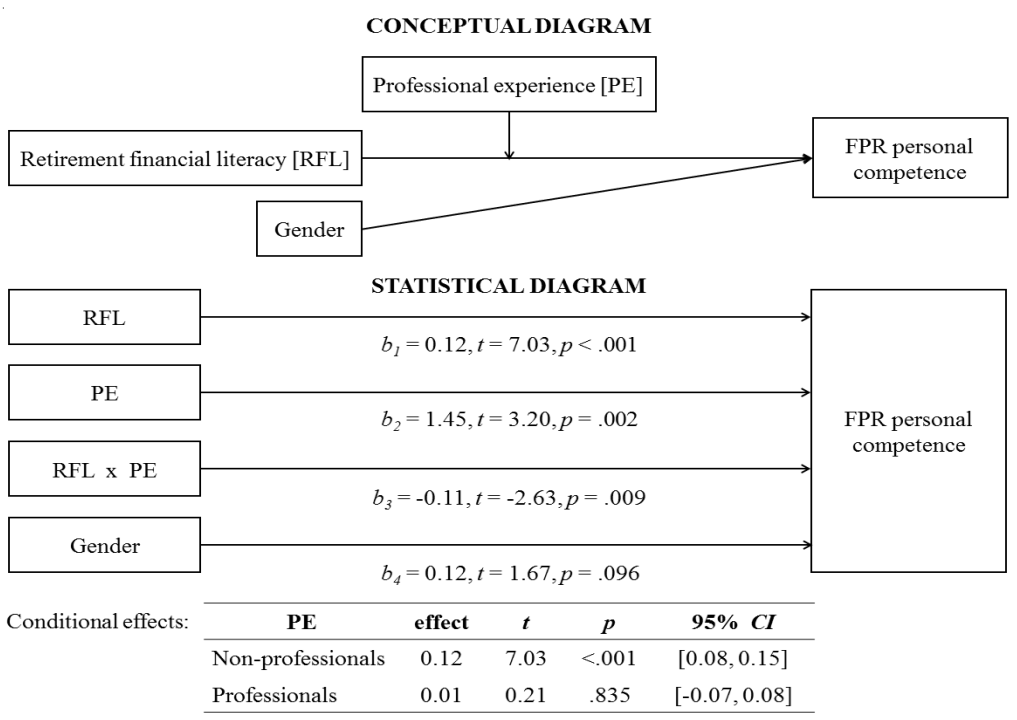

Figure 1 Professional experience as a moderator of the effect of retirement financial literacy on FPR personal competence

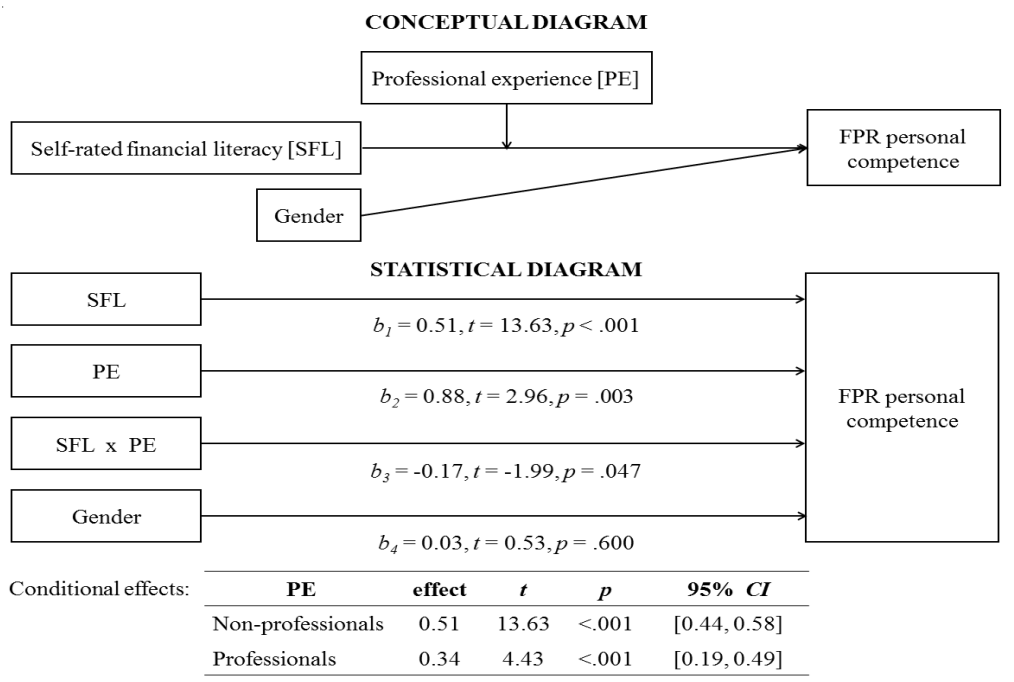

Figure 2 Professional experience as a moderator of the effect of self-rated financial literacy on FPR personal competence 


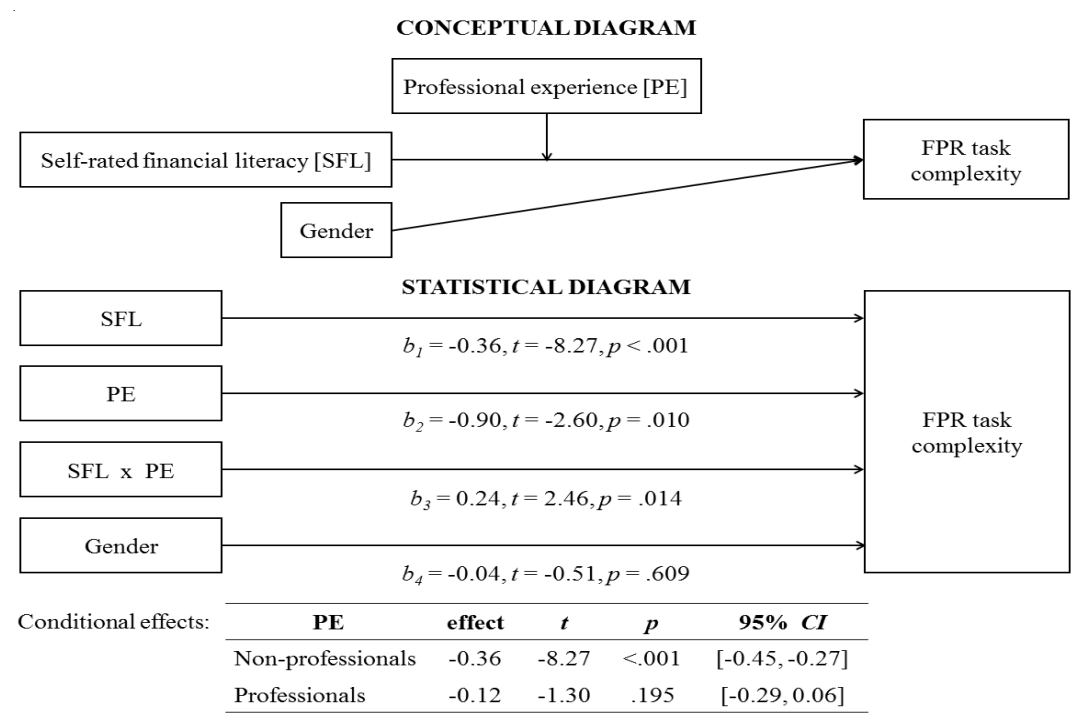

Figure 3 Professional experience as a moderator of the effect of self-rated financial literacy on FPR task complexity

\section{Discussion}

What is the role of professional experience with financial matters in preparation of young people for retirement? Since within any experience, one's knowledge, skills, attitudes, and beliefs are being synchronously threaded, the most direct route to acquire all these components is to perform the relevant activities professionally. This was the reason which led us to examine financial professionals and to compare them with non-professionals in their financial knowledge and beliefs.

We found that our samples of people working in financial versus non-financial professions exhibited similar levels of general financial literacy - both self-rated and objectively measured. Engagement of the two groups in the current retirement savings did not differ either. However, financial professionals demonstrated greater knowledge of the overall retirement financial system in Slovakia, which suggests that performing finance-related professions might provide better familiarity with financial planning for retirement (FPR).

Further, we were interested whether professional experience of young adults in financial domain is reflected in their beliefs about FPR. Financial professionals expressed being more competent but less personally engaged in FPR compared with self-assessment of their counterparts. Trust in the $2^{\text {nd }}$ pillar as well as perceived FPR task complexity and FPR emotional load did not differ by professional experience.

As for the link between financial knowledge and beliefs about FPR, the patterns in the two samples were fundamentally different. The ab- 
sence of professional experience in financial domain induced that financial knowledge and FPR beliefs of our participants were congruent and in a predicted manner. Thus, the higher financial literacy of non-professionals (especially with regard to knowledge of the local retirement financial system), the more they evaluated the $2^{\text {nd }}$ pillar in a positive manner, felt more competent and personally engaged in FPR, and considered FPR as less complex and emotionally loaded. The surprising finding was that objective financial knowledge and beliefs about FPR were not interconnected in the sample of financial professionals. However, the more professionals rated themselves as financially literate, the less anxious and the more competent they felt regarding FPR, and the higher FPR personal engagement they perceived.

For a deeper insight into the conditions of financial preparation for retirement we examined the impact of professional experience on the link between financial literacy and FPR beliefs via moderation analyses, controlling for the effect of gender. Professional experience moderated the effects of both self-rated and retirement financial literacy on FPR personal competence, and the effect of self-rated financial literacy on FPR task complexity. The three effects were substantially higher among non-professionals. However, the rest of the models showed that professional experience does not affect the strength of the relationships between financial knowledge and trust in the $2^{\text {nd }}$ pillar, FPR personal engagement and FPR emotional load. We hypothesize that the groups of professionals and non-professionals might have differed in some aspects beyond the scope of our study which are relevant for congruency between knowledge and beliefs in FPR domain.

We believe that explanation of our findings should be sought mainly in the professional experience character and the level of education of our participants. In our case, being a financial professional meant approximately six years work experience with calculation of wages and salaries and other similar medium-range economic matters. At the same time, more than half of the financial professionals and non-professionals completed a university degree which does not correspond to the proportion of university-educated people in Slovak population. All participants were regular internet users, so their computer literacy was also high. This might be the reason why both professionals and non-professionals in our study exhibited exceptionally good performance in the objective financial literacy tests, which differentiate sufficiently in general population.

People who work long enough in the same profession are customarily expected to have a sufficient amount of experience in the field. Shanteau, Weiss, Thomas, and Pounds (2003) stated accordingly: "presumably, no one can work as a professional for any length of time if they are incompetent" (p. 622). The presumption also implies that a person working in the profession for a long time is endowed with a structured knowledge, distinguishes between relevant and irrelevant knowledge, perseveres in seeking and processing information to a far greater extent than beginners in the field, etc. However, as demonstrated by recent research studies, a wealth of experience in certain field is not necessarily related to the quality of professional performance in this field. The knowledge of long-term employees can be superficial and inadequate in volume and depth, and therefore insufficient for a high level of performance and expertise (Ericsson, 2009; Shanteau et al., 2003). Therefore, we might expect a great variability in the group of professionals or even a low level of specific performance.

Our sample of financial professionals did not perform better in general financial literacy tests compared with non-professionals. This is counterintuitive, since they were expected to possess higher skills in working with numbers, financial procedures, etc., as well as to be more 
knowledgeable in financial matters. Interestingly, unlike the consistency of the objective and subjective measure of financial literacy in the non-professional group, self-reported level of financial knowledge did not correspond to the actual performance among professionals. It is not clear whether they expressed a lack of self-reflection or whether the common rule applies here: the more knowledgeable people are, the more they realize how little they actually know.

However, our professionals knew more about the local retirement financial system compared with their counterparts. We assume that they are more familiar with the complexity and uncertainty associated with FPR as well. It also seems that the specific financial professions included in the study brought beliefs about a retirement system, which were more nuanced, more differentiated and more ambiguous. These young adults employed in financial positions may possess a more realistic and maybe more skeptical view on FPR possibilities. We speculate that it was this particular insight into the pension scheme that evoked vacillation of beliefs about financial planning for retirement and resulted in weak associations between financial knowledge and beliefs about FPR. It is possible that the relationship knowledge-beliefs diminishes (or even reverses) after retirement financial literacy reaches some threshold in other populations as well. Perhaps a more targeted sample of professionals and inclusion of "real" financial experts could be beneficial in answering these questions. Further evidence is also needed as a contribution to the debate on crucial factors in FPR.

Some limitations of our present study should be addressed in future research. Only educated young people participated in the study. In addition, a different approach to data gathering in the two samples might also be taken into account. Nevertheless, we believe that we shed light on the role of professional experience in processes of financial planning for retirement. Moreover, our Beliefs about FPR scale might serve as a useful instrument for further studies in this field. From an applied perspective, our findings highlight the need to carefully consider the character of financial experience of individuals and to define precisely what professionality in financial domain means.

\section{Conclusion}

Not only knowledge, but also beliefs about the domain and interconnections between them come into play in financial decision making. Professional experience in financial domain does not necessarily increase factual financial knowledge or positive beliefs. It may even disrupt the coherent combination of the two components. And therefore, educating, counseling, and intervention efforts aimed at promoting financial preparation for retirement should be tailored to different target groups on the basis of their previous experience.

\section{References}

Ajzen, I., \& Fishbein, M. (2000). Attitudes and the attitude-behavior relation: Reasoned and automatic processes. European Review of Social Psychology, $11,1-33$.

Bucher-Koenen, T., \& Lusardi, A. (2011). Financial literacy and retirement planning in Germany. Journal of Pension Economics and Finance, 10, 565584

Čavojová, V., \& Hanák, R. (2014). How much information do you need? Interaction of intuitive processing with expertise. Studia Psychologica, 56(2), 83-97.

Croy, G., Gerrans, P., \& Speelman, C. (2010). The role and relevance of domain knowledge, perceptions of planning importance, and risk tolerance in predicting savings intentions. Journal of Economic Psychology, 31, 860-871.

Ericsson, K. A. (2009). Enhancing the development of professional performance: Implications from the study of deliberate practice. In K. A. Ericsson (Ed.), Development of professional expertise: Toward measurement of expert performance and design of opti- 
mal learning environments (pp. 405-431). Cambridge University Press.

Fernández-López, S., Otero, L., Vivel, M., \& Rodeiro, D. (2010). What are the driving forces of individuals' retirement saving? Czech Journal of Economics and Finance, 60, 226-251.

Fishbein, M., \& Ajzen, I. (1975). Belief, attitude, intention, and behavior: An introduction to theory and research. Reading, MA: Addison-Wesley.

Hayes, A. F. (2013). An introduction to mediation, moderation, and conditional process analysis: A regression-based approach. New York: Guilford Press.

Hershey, D. A., Austin, J. T., \& Gutierrez, H. C. (2015) Financial decision making across the adult life span: Dynamic cognitive capacities and real-world competence. In T. M. Hess, J. Strough, \& C. E. Lockenhoff (Eds.), Aging and decision making: Empirical and applied perspectives (pp. 329-349). Waltham, MA: Academic Press.

Hershey, D. A., Henkens, K., \& Dalen, H. P. (2010). Aging and financial planning for retirement: Interdisciplinary influences viewed through a cross-cultural lens. International Journal of Aging and Human Development, 70, 1-38.

Hershey, D. A., Jacobs-Lawson, J. M., McArdle, J. J., Hamagami, A. (2007). Psychological foundations of financial planning for retirement. Journal of Adult Development, 14, 26-36.

Hibbert, A., Lawrence, E. R., \& Prakash, A. J. (2012). The role of financial education in the management of retirement savings. Journal of Behavioral Finance, 13, 299-307.

Hofer, B. K., \& Pintrich, P. R. (1997). The development of epistemological theories: Beliefs about knowledge and knowing and their relation to learning. Review of Educational Research, 67, 88140 .

Lusardi, A., \& Mitchell, O. S. (2011a). Financial literacy and retirement planning in the United States. Journal of Pension Economics and Finance, 10, 509-525.

Lusardi, A., \& Mitchell, O. S. (2011b). Financial literacy around the world. An Overview Journal of Pension Economics and Finance, 10, 497-508.

Mayer, R. E. (2009). Advances in specifying what is to be learned: Reflections on the themes in chapters 6-8. In K. A. Ericsson (Ed.), Development of professional expertise: Toward measurement of expert performance and design of optimal learning environments (pp. 203-214). Cambridge University Press.

Noone, J. H., Stephens, C., \& Alpass, F. (2010). The process of Retirement Planning Scale (PRePS): Development and validation. Psychological Assessment, 22, 520-531.

Payne, J. W., Bettman, J. R., \& Johnson, E. J. (1993). The adaptive decision maker. Cambridge University Press.

Shanteau, J., Weiss, D. J., Thomas, R.P., \& Pounds, J. (2003). How can you tell if someone is an expert? Performance-based assessment of expertise. In S. L. Schneider \& J. Shanteau (Eds.), Emerging perspectives on judgment and decision research (pp. 620639). Cambridge University Press.

Van Rooij, M. J., Lusardi, A., \& Alessie, R. M. (2011). Financial literacy and retirement planning in the Netherlands. Journal of Economic Psychology, 32, 593-608.

\section{Appendix}

Items that comprise the five subscales of Beliefs about financial planning for retirement scale:

\section{TRUST IN THE $2^{\text {nd }}$ PILLAR}

1. Saving in the second pillar does not improve my standard of living in retirement. (R)

2. Saving in the second pillar is useless because it is only filling the treasure chest of private institutions. (R)

\section{FPR PERSONAL COMPETENCE}

3. I understand the information about saving for retirement, available to me.

4. I know very well how to plan my personal finances to sustain my pension.

5 . I know more than my peers about how to financially prepare for retirement.

6. In financial matters I am not confident enough to prepare myself adequately for retirement. $(\mathrm{R})$ 


\section{FPR PERSONALENGAGEMENT}

7. Financial planning for retirement is necessary since entering the first employment.

8. That's enough to start in middle age, i.e. in my forties, with my financial preparation for retirement. (R)

9. If I do not deal with my financial preparation for retirement now, I squandered a chance for a decent pension.

10. It is still too early for me to address the issue of financial preparation for retirement. (R)

11. I look at what I can do now to make financially secure retirement for me.

12. I do not address financial preparation for retirement, because I now have too many other problems to deal with. (R)

13. I delay deciding on the financial preparation for retirement for as long as possible. (R)

\section{FPR TASK COMPLEXITY}

14. The decision to participate in the second pillar requires a lot of effort.

15. Participation in the second pillar requires tracking changes in laws.

16. It seems to me that entering into second pillar is difficult paperwork.

17. Saving in the second pillar is discouraging for me as it requires more knowledge about investing than I have now.

18. Choosing the option of financial preparation for retirement is very difficult for me.

\section{FPR EMOTIONAL LOAD}

19. The long-term financial planning is stressful for me.

20. The daily decisions about money are a great burden for me.

21. I do not have sufficient income to save for my retirement.

22. Thinking about retirement makes me nervous.

23. In the area of my personal finances I live from day to day.

Note. Items marked with (R) were reverse coded. 